\title{
KANDUNGAN FLUORIDE DALAM AIR MINUM ISI ULANG DI KOTA BATAM
}

\author{
Nurlinda Ayu Triwuri ${ }^{1 *}{\text { dan } \text { Hazimah }^{2}}^{2}$ \\ ${ }^{1}$ Program Studi Teknologi Rekayasa Pengendalian Pencemaran Lingkungan Politeknik Negeri Cilacap, \\ Jalan Dr. Soetomo No.1 Sidakaya,Cilacap 55212. \\ ${ }^{2}$ Universitas Putera Batam, Jalan R.Soeprapto Tembesi, Batam-Kepulauan Riau \\ *Email: nurlindaayutriwuri@gmail.com
}

\begin{abstract}
Water needs are very good for humans because they are human body-forming substances. Public awareness of getting water that meets health requirements is increasing. People tend to choose more practical methods with relatively low costs in meeting drinking water needs, especially in the city of Batam. One of the fulfillment of drinking water needs that is an alternative is to use refill drinking water. The source of raw water for drinking water in the city of Batam comes from reservoir water. Water is a source of high fluoride intake. Thus, fluoride levels in water used for consumption must be considered so as not to overdo it. Fluoride is a highly reactive halogen, so it is always obtained in the form of compounds. Inorganic fluorides are toxic and more irritant than organic ones. Chronic poisoning causes people to become thin, disrupted body growth, dental fluorosis and skeletal and digestive disorders that can be accompanied by dehydration. The method used in this study is simple randomized sampling. The standard method of analysis for fluoride parameters (F) is the 4500-F-D method (SPADNS colorimetric method) used in the laboratory of PT. Sucofindo Batam. Laboratory test results of PT. Sucofindo Batam from the six refill drinking water samples taken, namely Fun Qua Batu Ampar, Salsabila Batam Center, Pak De Qua Tiban, Fresh Qua, Bengkong and Salwa Qua Tembesi obtained results of fluoride level analysis of $<0.06$ $\mathrm{mg} / \mathrm{L}$. While the results of fluoride level analysis from Alam Qua Piayu were obtained at $0.43 \mathrm{mg}$ / L. Refill water treatment from 6 locations of drinking water depots based on by Regulation of the Minister of Health No. 492 of 2010 still meets the quality standards set at $1.5 \mathrm{mg} / \mathrm{L}$.
\end{abstract}

Keywords: Fluoride (F), Refill drinking water

\section{Pendahuluan}

Manusia membutuhkan air untuk berbagai macam keperluan seperti mandi, memasak dan yang paling penting untuk konsumsi sehari-hari (Pradana, Y.A, 2013). Kebutuhan air sangat mutlak bagi manusia karena merupakan zat pembentuk tubuh manusia yang terbesar yaitu 685 dari bagian tubuh manusia. Kebutuhan air minum setiap orang bervariasi dari 2,1 liter hingga 2,8 liter per hari (Rahayu,C.S dkk, 2013).

Air dan kesehatan merupakan dua hal yang saling berhubungan. Kualitas air yang dikonsumsi masyarakat dapat menentukan derajat kesehatan masyarakat tersebut, khususnya air untuk minum dan makan (Agmalia, D dkk, 2013). Air minum selain merupakan kebutuhan esesensial, juga berpotensi sebagai media penularan penyakit, keracunan dan sebagainya (Mujianto, B dkk, 2015).

Pada era sekarang ini kesadaran masyarakat untuk mendapatkan air yang memenuhi syarat kesehatan semakin meningkat. Masyarakat cenderung memilih cara yang lebih praktis dengan biaya yang relatif murah dalam memenuhi kebutuhan air minum terutama di kota Batam. Salah satu pemenuhan kebutuhan air minum yang menjadi alternatif yaitu dengan menggunakan air minum isi ulang. Depot air minum adalah usaha industri yang melakukan proses pengolahan air baku menjadi air minum dan menjual langsung kepada konsumen (Pradana, Y.A, 2013).

Air minum isi ulang merupakan salah satu jenis air minum yang dapat langsung diminum tanpa dimasak terlebih dahulu, karena telah mengalami proses pemurnian baik secara 
penyinaran ultra violet, ozonisasi atau pun keduanya.

Proses pemurnian dengan ultra violet dapat membunuh bakteri tanpa meninggalkan sisa radiasi dalam air, sedangkan proses ozonisasi merupakan oksidator kuat yang bereaksi cepat dengan hampir semua zat organik (Rosita.Nita, 2014).

Sumber air baku air minum bisa berasal dari waduk, air hujan, air tanah dan lain sebagainya. Air tanah kaya akan fluorida biasa terdapat di daerah batuan dasar mengandung mineral fluoride. Batuan bawah permukaan di suatu daerah mengontrol zona di pelapukan yang dapat mempengaruhi batuan induk dalam mineral. Namun sumber air di kota Batam, sebagai sumber baku air minum sesuai dengan peruntukannya berasal dari air waduk.

Air merupakan salah satu sumber asupan fluorida yang cukup tinggi. Dengan demikian, kadar fluorida dalam air yang digunakan untuk dikonsumsi haruslah diperhatikan agar tidak berlebihan. Air minum dengan kadar fluorida \pm 0,4 ppm pada daerah tropis sudah dapat menimbulkan fluorisis, terkait dengan konsumsi air yang lebih tinggi dibandingkan dengan daerah beriklim dingin (Astriningrum, Y, $2010 \mathrm{dkk}$ ).

Fluorida merupakan halogen yang sangat reaktif, karenanya dialam selalu didapat dalam bentuk senyawa. Fluorida anorganik bersifat toksik dan lebih irritan daripada yang organik. Keracunan khronis menyebabkan orang menjadi kurus, pertumbuhan tubuh terganggu, terjadi fluorosis gigi serta kerangka dan gangguan pencernaan yang dapat disertai dehidrasi. Pada kasus keracunan berat akan terjadi cacat tulang, kelumpuhan dan kematian. Dari penelitian terbaru sebelumnya tentang senyawa fluorida pada tikus memperlihatkan adanya hubungan bermakna antara fluorida dengan kanker tulang (Agmalia, D dkk, 2013). Pada konsentrasi yang lebih yang lebih kecil 1,5 ppm fluorida sangat bermanfaat bagi kesehatan gigi. Pada konsentrasi lebih besar dari 2 ppm dapat menyebabkan kerusakan gigi. Fluoride pada konsentrasi 3 -6 menyebabkan kerusakan pada struktur tulang (Aziz. T, et all, 2013)

Berdasarkan dari hal tersebut, sangat jelas terlihat bahwa air minum adalah merupakan salah satu sumber resiko yang cukup dominan untuk kesehatan masyarakat, khususnya jika mengkonsumsi air minum tidak memenuhi syarat kimia baik akut maupun kronis serta dimungkinkan adanya resiko dari senyawa yang bersifat karsinogenik atau penyebab kanker. Sehingga dirasa perlu untuk melakukan Uji Kandungan Fluoride dalam Air Minum Isi Ulang khususnya di kota Batam.

\section{Landasan Teori}

Unsur fluorin dalam mineral yang diperkaya fluor melarut secara bertahap di air tanah, dan menjadi salah satu elemen utama. Secara umum, mineral fluorida sedikit larut dalam air. fluor bebas tidak stabil dan tidak berperan dalam toksikologi karena bereaksi segera dari komposisi fluoride.

Kehadiran fluorida terlarut hanya mungkin di bawah kondisi fisiko-kimia yang menguntungkan dan ketika waktu tinggal cukup lama. Di antara semua mineral yang kaya fluoride, fluorit paling banyak dan terjadi di hampir semua batuan dan mineral detrital. kimia, fluoride dan ion $\mathrm{OH}$ bermuatan negatif dan juga memiliki ukuran ion hampir serupa. karenanya, selama reaksi kimia, fluoride dapat dengan mudah menggantikan ion $\mathrm{OH}$ dalam banyak batuan yang membentuk mineral. Dalam proses pelapukan, hidrolisis, disosiasi dan pembubaran terjadi seiring berjalannya waktu. misalnya, jika air tanah kaya $\mathrm{HCO}_{3}$, jenis reaksi berikut terjadi selama interaksi air-mineral (fluorit):

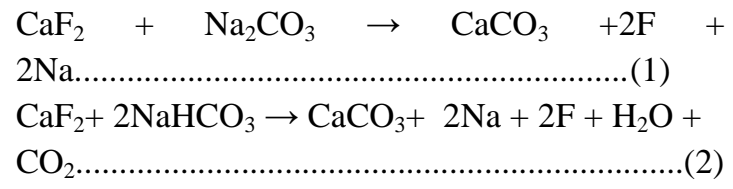

Dalam reaksi di atas, $\mathrm{NaHCO}_{3}$ kaya air dalam formasi batuan lapuk mempercepat pembubaran $\mathrm{CaF}_{2}$ untuk melepaskan fluorida ke dalam air tanah dengan waktu. Dalam reaksi ini, konsentrasi spesies ion terlarut dan $\mathrm{pH}$ air memainkan peranan penting. Mineral yang kaya akan kalsit $\left(\mathrm{CaCO}_{3}\right)$ juga memberi rasa disosiasi fluoride dari mineral kaya fluoride, dan ini dapat ditunjukkan sebagai berikut :

$\mathrm{CaCO}_{3}+\mathrm{H}+2 \mathrm{~F} \rightarrow \mathrm{CaF}_{2}+\mathrm{HCO}_{3}$

$\mathrm{CaF}_{2} \rightarrow \mathrm{Ca}+2 \mathrm{~F}$

( Ahmed,S, et all,2001) 
Unsur fluorin (F) merupakan elemen yang paling ringan dalam kumpulan halogen dan antara elemen yang paling reaktif. Fluorin merupakan elemen yang paling elektronegatif dari semua elemen yaitu bermaksud bahwa fluorin mempunyai kecenderungan yang kuat untuk menjadi cas negatif dan menjadi ion $\mathrm{F}^{-}$didalam larutan.

Kandungan fluorin dalam sampel air minum dipengaruhi oleh seperti ketersediaan dan kelarutan mineral yang mengandung fluor, porositas batuan atau tanah yang melaluinya lewatnya air dari elemen lain, misalnya kalsium, aluminium dan zat besi, yang dapat bergabung dengan fluor. (Ambarkova.,V, et all, 2007)

Fluorida ini merupakan senyawa kimia yang unik bila berlebihan terdapat di dalam air minum bisa berbahaya bagi kesehatan yaitu bisa mengakibatkan fluorisis gigi dan tulang, dan bila jumlahnya kurang didalam air minum juga bisa berbahaya bagi kesehatan yaitu mengakibatkan karies gigi (Agmalia,D dkk,2013) serta pada konsentrasi tertentu dapat menghambat kerja enzim peroksidase air liur. Air liur mengandung berbagai komponen yang berguna, selain sebagai pelumas makanan pada proses penelanan, air liur juga mengandung sejumlah bahan yang mempunyai fungsi biologis, seperti pada sistem kekebalan terhadap bakteri yang masuk melalui mulut.

Fluor dalam mencegah karies gigi perlu dicermati metoda pemberiannya. Hal tersebut karena secara mekanisme fluor dapat menghambat kerja enzim rongga mulut terutama sistem peroksidase air liur yang berfungsi mengahambat kerusakan gigi lebih lanjut (Djamil,M.S, 2000).

Mekanisme fluor dalam menghambat karies gigi adalah karena ion fluor menghambat kerja enzim pada jalur glikolisis. Ion fluor dalam cairan rongga mulut akan berikatan dengan ion magnesium, membentuk magnesium fluoride. Magnesium merupakan ion yang dibutuhkan bersama enolase mengubah 2P-gliserat menjadi fosfoenolpiruvat. Akibat hembatan oleh $\mathrm{F}$, glikosis pada sel bakteri di hambat, bakteri tidak menghasilkan energi cukup dan perkembangan bakteri terhambat (Djamil,M.S, 2000).

\section{Metode Penelitian}

Metode yang digunakan dalam penelitian ini adalah simple randomized sampling. Lokasi depot air isi ulang yang digunakan sebagai sampel diantaranya daerah piayu, tembesi, batam center, tiban, batu ampar dan bengkong. Metode analisa yang digunakan berdasarkan Standart Methods for Water and Waste Water American Public Health Assosiation, 22 $2^{\text {nd }}$ eddition 2012 dan standar analisa untuk parameter fluoride $(\mathrm{F})$ yakni metode 4500-F- D (SPADNS colorimetric method) yang digunakan di laboratorium PT. Sucofindo Batam.

\section{Metode 4500-F- D (SPADNS colorimetric method)}

Prinsip metode kolorimetri SPADNS-asam zirkonil yaitu ketika jumlah fluoride meningkat, warna yang dihasilkan menjadi semakin lebih ringan laju reaksi antara ion fluoride dan zirkonium sangat dipengaruhi oleh keasaman campuran sampelnya. Pemilihan pewarna untuk metode fluoride cepat ini sangat dipengaruhi oleh toleransi yang dihasilkan terhadap ion-ion ini. Metode kolorimetri dengan spektrofotometer dengan peraksi SPADNS untuk mengetahui kadar fluorida dalam air isi ulang (Greenberg,A.E,1992).

\section{Pembahasan}

\subsection{Hasil Laboratorium}

Hasil pemeriksaan kadar fluoride $(\mathrm{F})$ pada 6 sampel air dari depot air minum isi ulang di kota Batam dapat dilihat pada Tabel 4.1 berikut :

Tabel 4.1. Hasil laboratorium Air Minum Depot Isi Ulang (AMDIU) berdasarkan kadar fluoride

\begin{tabular}{|c|c|c|c|}
\hline $\begin{array}{l}\text { Air minum } \\
\text { depot isi } \\
\text { ulang }\end{array}$ & $\begin{array}{l}\text { Hasil } \\
\text { Analisa } \\
(\mathrm{mg} / \mathrm{L})\end{array}$ & $\begin{array}{l}\text { Baku } \\
\text { Mutu } \\
\text { (mg/L) }\end{array}$ & Metode \\
\hline $\begin{array}{l}\text { Fun Qua } \\
\text { Batu Ampar } \\
\text { Salsabila }\end{array}$ & $<0,06$ & 1,5 & $4500-\mathrm{F}-\mathrm{D}$ \\
\hline $\begin{array}{l}\text { Batam } \\
\text { Centre }\end{array}$ & $<0,06$ & 1,5 & $4500-F-D$ \\
\hline $\begin{array}{l}\text { Pak De Qua } \\
\text { Tiban }\end{array}$ & $<0,06$ & 1,5 & $4500-F-D$ \\
\hline $\begin{array}{l}\text { Alam Qua } \\
\text { Piayu }\end{array}$ & 0,43 & 1,5 & $4500-F-D$ \\
\hline $\begin{array}{l}\text { Fresh Qua } \\
\text { Bengkong }\end{array}$ & $<0,06$ & 1,5 & $4500-\mathrm{F}-\mathrm{D}$ \\
\hline $\begin{array}{l}\text { Salwa Qua } \\
\text { Tembesi }\end{array}$ & $<0,06$ & 1,5 & $4500-F-D$ \\
\hline
\end{tabular}

\subsection{Pembahasan hasil laboratorium}

Dari hasil uji laboratorium PT. Sucofindo Batam dari ke enam sampel air minum depot isi 
ulang yang diambil yaitu Fun Qua Batu Ampar, Salsabila Batam Centre, Pak De Qua Tiban, Fresh Qua Bengkong dan Salwa Qua Tembesi diperoleh hasil analisa kadar fluoride sebesar < 0,06 mg/L. Sedangkan hasil analisa kadar fluoride dari Alam Qua Piayu diperoleh sebesar 0,43 mg/L. Hal ini masih sesuai dengan di bawah standar baku mutu yang ditetapkan sebesar 1,5 mg/L. Pengolahan air isi ulang dari 6 lokasi depot air minum berdasarkan dari Permenkes No. 492 Tahun 2010 masih memenuhi baku mutu yang ditetapkan.

\section{Kesimpulan dan Saran}

\subsection{Kesimpulan}

Hasil analisa kadar fluoride dari ke enam (6) sampel air minum depot isi ulang yang diambil yaitu Fun Qua Batu Ampar, Salsabila Batam Centre, Pak De Qua Tiban, Fresh Qua Bengkong dan Salwa Qua menghasilkan sebesar $<0,06$ $\mathrm{mg} / \mathrm{L}$. Sedangkan hasil analisa kadar fluoride dari Alam Qua Piayu diperoleh sebesar 0,43 mg/L masih berada di bawah standar baku mutu yang ditetapkan oleh Permenkes No. 492 Tahun 2010 yaitu $1,5 \mathrm{mg} / \mathrm{L}$.

\subsection{Saran}

Adapun saran dalam penelitian ini adalah perlunya melakukan penelitian lanjutan tentang kualitas air dari sumber air baku di kota Batam.

\section{Daftar Referensi}

Agmalia. D, Hamidy. R., Anita. S (2013). Uji Escherichia Coli dan Fluorida Air Minum Bungkusan Plastik Pada Rumah Makan di Kecamatan Rumbai Pesisir Pekanbaru. Pusat Penelitian Lingkungan Hidup Universitas Riau.

Ahmed. S, and Saxena.V.K. (2001). Dissolution of Fluoride in Groundwater : A Water-Rock Interaction Study, Jurnal Environmental Geology, $40 \quad$ : 1084-1087. DOI. $10.1007 / \mathrm{s} 002540100290$.

Ambarkova. V, Topitsoglou. V, Iljovska. S, Jankulovska . M, Pavlevska. M. (2007). Fluorine Content of Drinking Water in Relation to the Geological - Petrographical Formations From FYROM, Balkan Journal Of Stomatology, ISSN 1107-1141.
Astriningrum.Y, Suryadi. H, Azizahwati. (2010). Analisa Kandungan Ion Fluorida Pada Sampel Air Tanah dan Air PAM secara Spektrofotometri, Majalah Ilmu Kefarmasian, Vol.VII, No.3, Desember 2010, 46-57. ISSN: 1693-9883. Universitas Indonesia FMIPA, Departemen Farmasi.

Aziz.T, Pratiwi.D.Y, Rethiana. L. (2013). Pengaruh Penambahan Tawas Al2(SO4)3 dan Kaporit $\mathrm{Ca}(\mathrm{Ocl}) 2$ Terhadap Karakteristik Fisik dan Kimia Air Sungai Lambidaro. Jurnal Teknik Kimia No.3, Vol.19, Agustus 2013. Hal $55-65$.

Djamil. S.M, Mekanisme Fluor Menghambat Kerja Enzim Air Liur, Jurnal Kedokteran Gigi Universitas Indonesia ISSN 0854-364X, (Edisi Khusus) Hal : 1-6.

Greenberg. A.E, Cleasceri.L.S and Eaton. A.D, "Standard Methods : For The Examination Of Water And Wastewater", $18^{\mathrm{TH}}$ Edition 1992, ISBN 0-87553-207-1, The Library of Congress has catalogued this work as follows, American Publich Health Association.

Mujianto. B, Purwanti.A, Rismini.S. (2015). Kandungan Besi Air Sumur di Perumahan Huma Akasia Jatiwarna - Pondok Melati, Bekasi. Jurnal Ilmu dan Teknologi Kesehatan. 2(2): 21-25.

Peraturan Menteri Kesehatan Republik Indonesia Tahun 2010 tentang Persyaratan Kualitas Air Minum. No. 492/MENKES/PER/IV/2010.

Pradana.Y.A dan Marsono. B.D. (2013). Uji Kualitas Air Minum Isi Ulang di Kecamatan Sukodono, Sidoarjo Ditinjau dari Perilaku dan Pemeliharaan Alat. Jurnal Teknik POMITS Vol. 2, No.2, 2013, ISSN: 2337-3539 (23019271 print)

Rahayu. C.S, Setiani, O dan Nurjazuli. (2013). Faktor Risiko Pencemaran Mikrobiologi pada Air Minum Isi Ulang di Kabupaten Tegal. Jurnal Kesehatan Lingkungan Indonesia Vol.12 No.1/April 2013.

Rosita. Nita. (2013). Analisis Kualitas Air Minum Isi Ulang Beberapa Depot Air Minum Isi Ulang (DAMIU) di Tangerang Selatan. Jurnal 
Kimia Valensi Vol.4 No.2, November 2014 (134-141) ISSN : 1978-8193. 